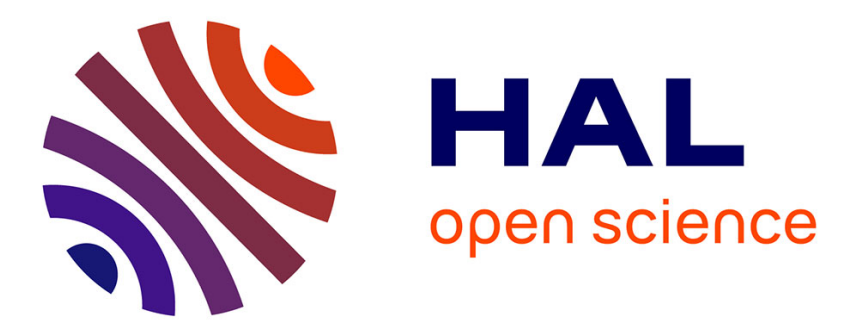

\title{
Experimental study and modelling approaches for the thermal conductivity evolution of hydrating cement paste
}

Pierre Mounanga, Abdelhafid Khelidj, Guy Bastian

\section{- To cite this version:}

Pierre Mounanga, Abdelhafid Khelidj, Guy Bastian. Experimental study and modelling approaches for the thermal conductivity evolution of hydrating cement paste. Advances in Cement Research, 2004, 16 (3), pp.95 - 103. 10.1680/adcr.2004.16.3.95 . hal-01006850

\section{HAL Id: hal-01006850 \\ https://hal.science/hal-01006850}

Submitted on 5 Mar 2017

HAL is a multi-disciplinary open access archive for the deposit and dissemination of scientific research documents, whether they are published or not. The documents may come from teaching and research institutions in France or abroad, or from public or private research centers.
L'archive ouverte pluridisciplinaire HAL, est destinée au dépôt et à la diffusion de documents scientifiques de niveau recherche, publiés ou non, émanant des établissements d'enseignement et de recherche français ou étrangers, des laboratoires publics ou privés.

\section{(c)(1)}

Distributed under a Creative Commons Attribution| 4.0 International License 


\title{
Experimental study and modelling approaches for the thermal conductivity evolution of hydrating cement paste
}

\author{
P. Mounanga, A. Khelidj and G. Bastian \\ Institut de Recherche en Génie Civil et Mécanique
}

Thermal stresses due to hydration heat release within concrete structures can lead to early age cracking particularly in cases of massive structures. In order to prevent, minimise and avoid this, a good knowledge of the evolution of cement-based material heat transfer properties at early stages of hydration is essential. In order to address the problem of the evolution of the thermal conductivity of fresh cement paste, two models developed by the authors are discussed: first, the 'apparent' thermal conductivity is calculated, assuming the fresh cement paste to be a multiphase material, which makes it possible to consider the material chemical evolution. The second modelling approach is based on the theory of heat and mass transfer within non-saturated porous media. The second modelling results appear to fit the experimental results better.
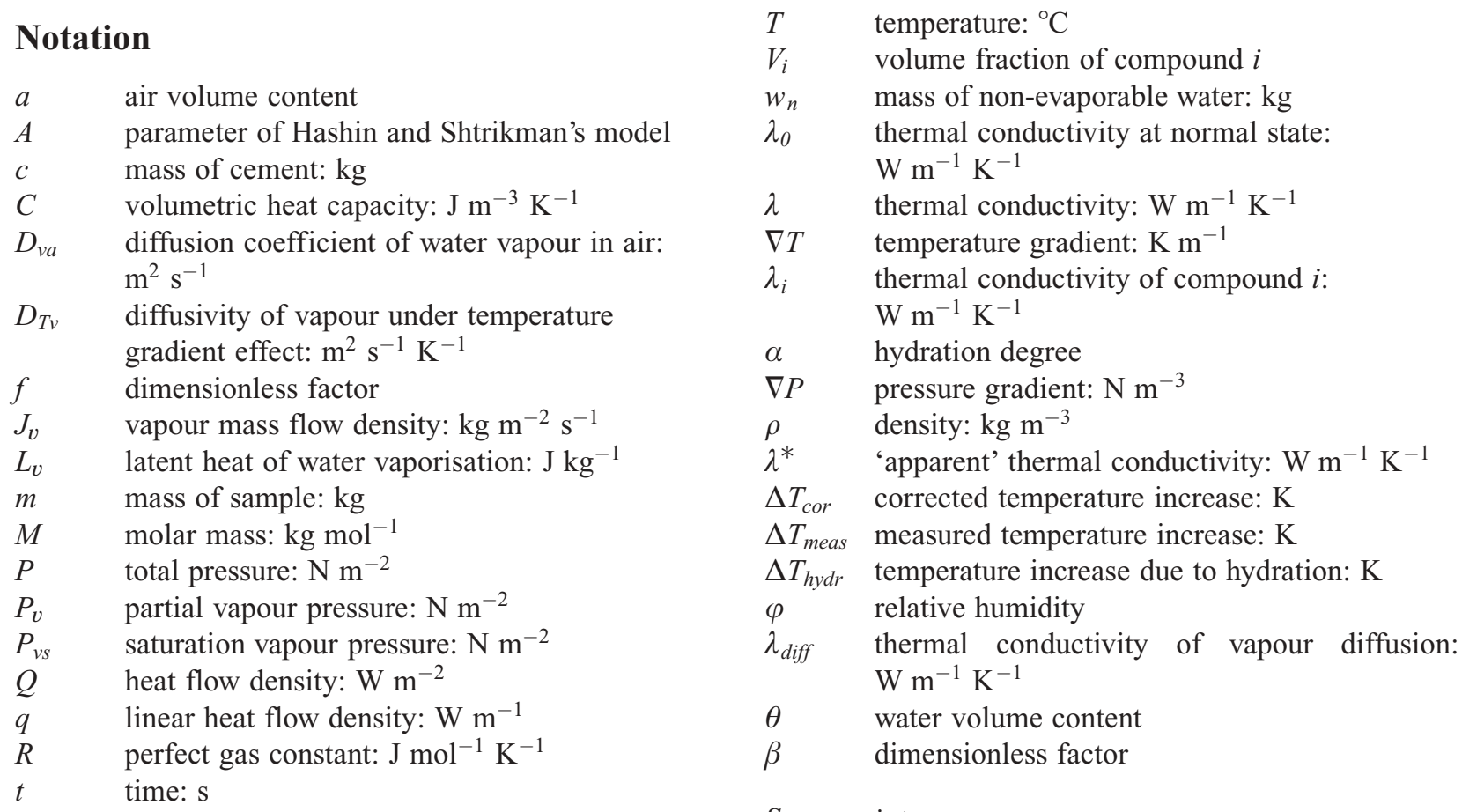

Superscripts

$c \quad$ consumed

i initial

Subscripts

$\begin{array}{ll}a & \text { air } \\ c & \text { cement }\end{array}$




$\begin{array}{ll}h & \text { hydrates } \\ m & \text { hydrate gel micropores } \\ w & \text { water }\end{array}$

\section{Introduction}

The hydration process of cement-based materials generates considerable heat release. Both exothermic and thermo-activated characteristics of the hydration reaction can cause cracking at early ages of the material and alter the durability of concrete structures, especially large ones.

The prevention of cracks requires a good understanding of the thermal behaviour of the material during hydration. The determination of concrete thermal properties in hardened state is extensively documented. $^{1-5}$ In comparison, very limited studies have been conducted to examine fresh material, when heat release occurs. ${ }^{6-8}$ These studies, however, reveal contradictory results.

The choice in this paper to study pure cement paste makes it possible to link the evolution of the thermal properties directly to both chemical and structural evolutions of the material. The study presented in this paper focuses on the evolution of the thermal conductivity of fresh ordinary cement paste (OPC).

The hydration processes are complex because anhydrous cement is a heterogeneous material. All the chemical phases have specific hydration kinetics and interact with one another. ${ }^{9}$ From a structural point of view, the negative volume balance, between reaction products (mainly calcium silicate hydrates, noted C$\mathrm{S}-\mathrm{H}$ ) and initial reactants, causes internal porosity and, therefore, introduces an internal water vapour phase.

The model of hydration, proposed by Powers and quoted by Neville ${ }^{10}$ and Taylor, ${ }^{11}$ is a simplification of this process, which assumes a global cement hydration degree and a linear production of $\mathrm{C}-\mathrm{S}-\mathrm{H}$ products according to this degree. Considering cement paste as a multiphase material and assigning, to each phase, the values of its own thermal properties, it is possible to estimate the thermal conductivity evolution of the material as a function of the chemical reaction progress (classical Maxwell's problem). The second approach consists in taking the microstructure of the material (formation of non-saturated internal porosity) into account and in assuming evaporation-condensation mechanisms. Philip and De Vries' analysis, ${ }^{12-14}$ is used to quantify the impact of these mechanisms on the thermal conductivity variations of wet porous materials.

Both modelling approaches have been applied to the case of OPC. The computed results are compared with the experimental results previously obtained using the 'hot wire method'.

\section{Experimental set-up}

Material

The cement used is an ordinary type I Portland cement (CPA CEM I 52.5 HTS), containing $63.3 \%$ of $\mathrm{C}_{3} \mathrm{~S}, 17 \cdot 9 \%$ of $\mathrm{C}_{2} \mathrm{~S}, 4 \cdot 7 \%$ of $\mathrm{C}_{3} \mathrm{~A}$ and $5 \cdot 6 \% \mathrm{C}_{4} \mathrm{AF}$. The Blaine specific surface is $3350 \mathrm{~cm}^{2} \mathrm{~g}^{-1}$. The water-tocement $(\mathrm{w} / \mathrm{c})$ ratio is $0 \cdot 348$. A 3 min mixing guarantees the homogeneity of the cement-water mixture. Immediately after mixing, the cement paste is poured into a PVC tube containing the two parallel wires.

\section{Thermal conductivity measurements}

'Hot wire method' and 'two wire method'. The method used here to determine the thermal conductivity of OPC is the 'two wire method'. It is an adaptation of the 'hot wire method'. The 'hot wire method' is a classical transient-type method. ${ }^{15}$ It consists in enforcing a heating rectangular pulse in a wire dived into the studied material. From temperature evolution versus time, thermal conductivity is determined using ( $\Delta$ being some linear variations)

$$
\lambda=\frac{q}{4 \pi} \frac{\Delta \ln \left(\frac{t}{t-t_{\text {heating }}}\right)}{\Delta T}
$$

where $\lambda$ is the thermal conductivity of the material (in $\left.\mathrm{W} \mathrm{m} \mathrm{m}^{-1} \mathrm{~K}^{-1}\right) ; q$ is the heat flow provided to the hot wire' (in $\mathrm{W} \mathrm{m} \mathrm{m}^{-1}$ ); $t$ is the time (in s); theating is the heating time (in s); and $T$ is the temperature (in $\mathrm{K}$ ).

The physical parameter measured here will be more properly called 'apparent' thermal conductivity of the material $\left(\lambda^{*}\right)$ since, as demonstrated by Moyne et al., ${ }^{16}$ this is the only value that transient-type methods can determine. The notion of 'apparent' thermal conductivity $\lambda^{*}$ will be clarified below.

Fitting specially building materials, variants of the 'hot wire method' were achieved by Bastian and Khelidj: ${ }^{6}$ the same probe was used simultaneously as a heat transmitter and as a temperature detector.

In the 'two wire method', a second wire is embedded, parallel to the first. From the temperature evolution of this second (non-heated) wire versus time, it becomes possible to determine the volumetric heat capacity $C$ (in $\mathrm{J} \mathrm{m}^{-3} \mathrm{~K}^{-1}$ ) of the material

$$
C=\frac{q}{e \pi r^{2}}\left(\frac{\Delta t}{\Delta T}\right)_{I}
$$

where $r$ is the distance between the two wires (in $\mathrm{m}$ ); and $I$ the inflexion point of the 'temperature versus time' evolution of the non-heated wire.

Test device. The test device is schematically illustrated in Fig. 1. Two stainless steel wires (Ø $0.5 \mathrm{~mm})$, insulated with a thermo-retractable sheath, are used as temperature sensors for measuring temperature variations. One of the wires is also used as a heat line source: every half hour, a 4 A current passes 


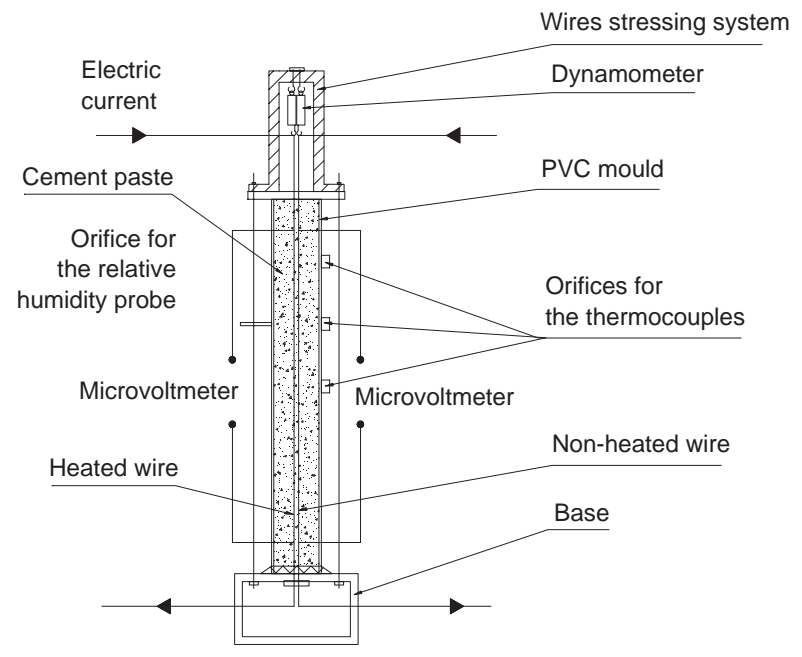

Fig. 1. Schematic diagram of the test device used for the measurement of fresh cement paste thermal conductivity

through the wire. A transformer linked to a potentiometer supplies the electric current. The duration of heating steps is $60 \mathrm{~s}$; between heating steps (and throughout the whole experiment for the non-heated wire), a much lower current $(80 \mathrm{~mA})$ is injected in both wires in order to generate the potential difference necessary to make voltage measurements. The evolution of the wire electrical resistance is determined by measuring voltage with a data logging system during heating and non-heating steps. From the previously determined 'resistance versus temperature' law of the wires, the evolution of their temperature and, therefore, of the 'apparent' thermal conductivity and the volumetric heat capacity of the material can be deduced. The theoretical development leading to the calculation of these thermal properties has been detailed by Bastian and Khelidj ${ }^{6}$ and by Carslaw and Jaeger. ${ }^{17}$

The exterior mould containing the fresh cement paste is a PVC tube $1200 \mathrm{~mm}$ long with a diameter of $160 \mathrm{~mm}$. A wire tensioning system is placed on both ends of the pipe to maintain an identical mechanical state $(50 \mathrm{~N})$ of both wires, which are placed symmetrically in relation to the cylinder axis. The distance between both wires is $15 \mathrm{~mm}$. Four other sensors are used

(a) three thermocouples, placed respectively at 200, 400 and $600 \mathrm{~mm}$ from the top of the PVC tube

(b) a relative humidity probe, which is inserted $25 \mathrm{~h}$ after the casting of the cement paste, inside an orifice bored with a steel rod $(\varnothing 5 \mathrm{~mm})$. This probe measures the decrease in the internal relative humidity due to the mixing water consumption inherent to the hydration process.

Once the paste has been cast, the mould is closed and sealed with silicone grease to prevent any mass exchanges between specimen and outside. The experiment is conducted in a temperature and relative humidity controlled room $\left(T=20 \pm 2^{\circ} \mathrm{C}\right.$, relative humidity $=50 \pm 5 \%$ ).

\section{Hydration degree measurements}

The evolution of the most important properties of cement paste (mechanical resistance, ${ }^{18}$ chemical shrinkage, ${ }^{19}$ hydration heat, ${ }^{20}$ etc.) are directly related to its degree of hydration. In order to establish a correlation between the evolution of the thermal properties of cement paste and the chemical changes induced by the hydration process the evolution of the hydration degree of cement paste is measured at the same time. For this purpose, prismatic specimens $(40 \times 40 \times 60 \mathrm{~mm})$ are prepared from the same batch as the cylindrical specimen. The method adopted here for the sealing of the prismatic samples consists in, first, wrapping the moulds with a plastic film in a damp cloth for $24 \mathrm{~h}$ and, then, in sealing the specimens with a resin layer and an aluminium adhesive tape after removal from the mould at $24 \mathrm{~h}$.

The hydration degree is determined on the basis that the hydration of $1 \mathrm{~g}$ of anhydrous cement produces $0 \cdot 23 \mathrm{~g}$ of non-evaporable water, a ratio calculated from Bogue's equation. $^{21}$ The non-evaporable water corresponds to the loss on ignition (LOI) of the hydrating cement paste sample between 105 and $1050^{\circ} \mathrm{C}$. $^{22}$ Finally, we obtain the following equation for the calculation of the hydration degree

$$
\alpha=\frac{w_{n}(t)}{0 \cdot 23 \cdot c} \times 100=\frac{w_{n}(t)}{0 \cdot 23 \cdot m} \cdot(1+w / c) \times 100
$$

where $\alpha$ is the hydration degree of cement paste (in $\%$ ); $w_{n}(t)$ is the mass (in $\mathrm{kg}$ ) of non-evaporable water measured at time $t ; c$ is the initial mass (in $\mathrm{kg}$ ) of anhydrous cement in the sample of cement paste; and $m$ the mass of this sample (in $\mathrm{kg}$ ).

The furnace used for the sample ignition is a type 6000 Thermolyne. For each measurement, three prismatic specimens are cut and two pieces $\left(1 \mathrm{~cm}^{3}\right)$ taken from each of these specimens to determine the hydration degree. $^{23}$

Figure 2 shows the evolution of the cement paste hydration degree as a function of time.

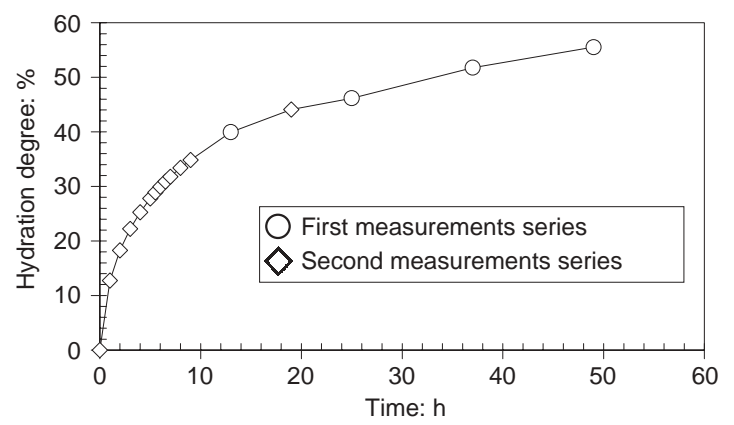

Fig. 2. Evolution of the hydration degree of cement paste (measured by loss on ignition) plotted against time 


\section{Results and discussion}

\section{Correction of the experimental results}

As mentioned in the introduction, cement paste is characterised, at early age (between 5 and $10 \mathrm{~h}$ after mixing), by an important heat release. This exothermic phenomenon disturbs measurement because the real temperature evolution of the wires is a combination of the Joule heat and the heat generated by the chemical reactions. Since the equations for the determination of the thermal conductivity only take the power supplied by the electric current into account, a correction is necessary to eliminate the influence of the hydration heat. A pure additive effect between the power generated by the hydration process and the one supplied by the electric current is considered here. Consequently, correcting the experimental results simply consists in deducting the temperature increase $\left(\Delta T_{h y d r}(t)\right)$ due to the hydration heat from the measured wire temperature increase $\left(\Delta T_{\text {meas }}(t)\right)$

$$
\Delta T_{\text {cor }}(t)=\Delta T_{\text {meas }}(t)-\Delta T_{\text {hydr }}(t)
$$

where $\Delta T_{c o r}(t)$ is the corrected temperature increase of the 'hot wire' (in $\mathrm{K}$ ). $\Delta T_{h y d r}(t)$ evolution is measured using the thermocouples embedded in the cement paste (see Fig. 3).

All the calculations, presented below, take this correction into account.

\section{Evolution of the 'apparent' thermal conductivity}

Two series of tests are carried out. The first series, conducted over a relatively long period (28 days), shows a variation of the 'apparent' thermal conductivity at early ages. In order to examine this variation, a second test series is performed over a much shorter period (the first $24 \mathrm{~h}$ after OPC casting). Figs 4(a) and 4(b) present the evolution of the 'apparent' thermal conductivity of cement paste. Three main phases are observed.

(a) From 0 to $6 \mathrm{~h}$ after mixing, the 'apparent' thermal conductivity remains nearly constant, at about $1.0 \mathrm{~W}$ $\mathrm{m}^{-1} \mathrm{~K}^{-1}$.

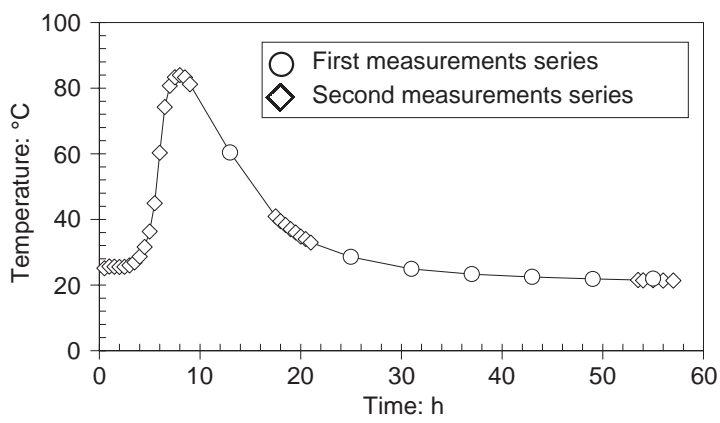

Fig. 3. Evolution of the internal temperature of fresh cement paste plotted against time

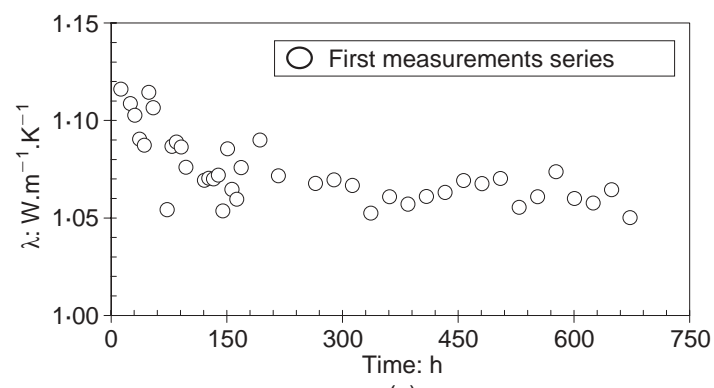

(a)

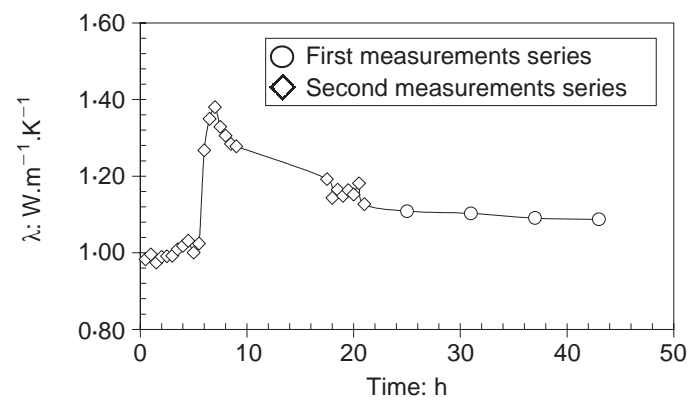

(b)

Fig. 4. Evolution of the measured 'apparent' thermal conductivity of cement paste (corrected results) plotted against time: (a) during 28 days; (b) during the first $24 \mathrm{~h}$ after casting

(b) At about $6 \mathrm{~h}$, the 'apparent' thermal conductivity shows a maximum value, of about $1.4 \mathrm{~W} \mathrm{~m}^{-1} \mathrm{~K}^{-1}$.

(c) After the peak, the 'apparent' thermal conductivity value decreases and finally stabilises at about $1 \cdot 1 \mathrm{~W}$ $\mathrm{m}^{-1} \mathrm{~K}^{-1}$

The final value of the 'apparent' thermal conductivity satisfactorily agrees with that of a previous study. ${ }^{24}$ However, nowhere in the literature can it be found any information about a peak in the evolution of cement paste thermal conductivity at very early age.

In order to explain this phenomenon, two different modelling approaches have been developed and compared with the experimental results.

\section{Modelling approaches}

\section{Linear chemical evolution model and classical Maxwell's problem}

This modelling approach consists in linking the evolution of the 'apparent' thermal conductivity directly to the chemical evolution of cement paste. The modelling principle is based on the classical Maxwell's problem: on the assumption of only pure conductive heat transfers, the 'apparent' thermal conductivity $\lambda^{*}$ of cement paste is estimated to be the equivalent thermal conductivity of a multiphase material

$$
\lambda^{*}=g\left(\lambda_{i}(T), V_{i}(\alpha)\right)
$$


where $\lambda_{i}$ and $V_{i}$ are the thermal conductivity (in $\mathrm{W} \mathrm{m}^{-1}$ $\mathrm{K}^{-1}$ ) and the volume fraction of phase $i$, respectively, $T$ is the temperature (in ${ }^{\circ} \mathrm{C}$ ); and $g$ the different types of multiphase models (series/parallel model, Hashin and Shtrikman's model, for example).

Considering the reactive behaviour of OPC, the volume fraction evolution of each phase has to be quantified, first. In order to express this evolution as a function of hydration degree $\alpha$, the Powers' model, quoted by Taylor, ${ }^{11}$ is used. This model integrates several hypotheses.

(a) The various and complex hydration reactions are represented by a global reactive balance (anhydrous cement + water $\rightarrow$ hydrates).

(b) The hydration of $1 \mathrm{~g}$ of anhydrous cement consumes $0.23 \mathrm{~g}$ of water.

(c) The absolute volume $V_{h}$ of hydrates, formed by reactions, is lower than the sum of anhydrous cement, $V_{c}^{c}$, and water, $V_{w}^{c}$, volumes consumed by hydration (Le Chatelier's contraction ${ }^{25}$ )

$$
V_{h}=\left(V_{c}^{c}+V_{w}^{c}\right)-0.254 \cdot V_{w}^{c}=V_{c}^{c}+0.746 \cdot V_{w}^{c}
$$

(d) The hydrate structure contains micro-pores, whose volume $V_{m}$ is expressed as

$$
\frac{V_{m}}{V_{m}+V_{h}}=0 \cdot 28
$$

Finally, the following equation system is obtained, for one volume unit of cement paste

$$
\left\{\begin{array}{l}
V_{c}=\frac{1}{1+\rho_{c} \cdot \frac{w}{c}}(1-\alpha) \\
V_{h}=1 \cdot 539 \frac{1}{1+\rho_{c} \cdot \frac{w}{c}} \cdot \alpha \\
V_{w}=V_{w}^{i}-V_{w}^{c}=\frac{\rho_{c} \cdot \frac{w}{c}}{1+\rho_{c} \cdot \frac{w}{c}}-0 \cdot 722 \frac{1}{1+\rho_{c} \cdot \frac{w}{c}} \cdot \alpha \\
V_{a}=1-\left(V_{c}+V_{h}+V_{w}\right)
\end{array}\right.
$$

where $V_{c}, V_{w}, V_{h}, V_{a}$ are the anhydrous cement volume fraction, the water volume fraction, the hydrate volume fraction and the gaseous volume fraction, respectively, present in cement paste at $\alpha \%$ of hydration and $\rho_{c}$ is the density of anhydrous cement $\left(\rho_{c}=3 \cdot 15 \mathrm{~g} \mathrm{~mm}^{-3}\right)$. Superscripts $c$ and $i$ are used for 'consumed' and 'initial', respectively.

Figure 5 shows the evolution of the volume fractions of hydration products and reactants calculated from equations (4-6) as a function of hydration degree, for a cement paste with a w/c $=0 \cdot 348$.

The thermal conductivity values of the different phases (anhydrous cement + hydrates, liquid water and air) are given in Table 1.

From equation (8) and the values of Table 1, it is possible to propose a framing of $\lambda^{*}$ value. Two approaches are considered.

(a) First, with disregard for the material structure, we have used the series/parallel models (Wiener bounds) whose lower limit is given by

$$
\lambda_{\perp}=\left(\sum_{i=1}^{n} \frac{V_{i}}{\lambda_{i}}\right)^{-1},(\text { series model })
$$

and upper limit by

$$
\lambda==\sum_{i=1}^{n} V_{i} \cdot \lambda_{i},(\text { parallel model })
$$

(b) Second, the structure of fresh cement paste is assumed isotropic and the more restrictive Hashin and Shtrikman's model is applied. The thermal conductivity $\lambda^{*}$ of the multiphase material is bounded by

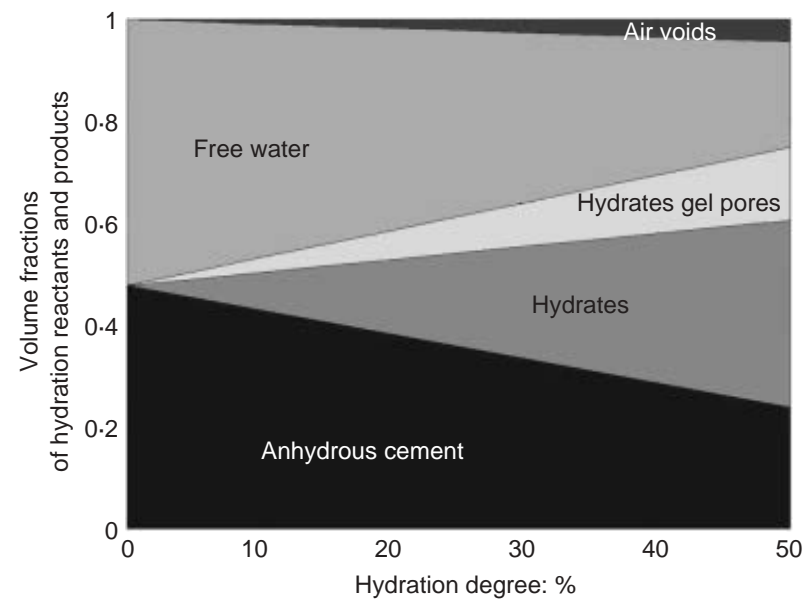

Fig. 5. Evolution of the volume fractions of hydration reactants and products computed using the model of Powers as a function of hydration degree cement paste with $w /$ $c=0.348$ between 0 and $50 \%$ of hydration

Table 1. Thermal conductivity values of the different phases of fresh cement paste

\begin{tabular}{l|c|l}
\hline Phase & $\begin{array}{c}\text { Thermal } \\
\text { conductivity: } \\
\mathrm{W} \mathrm{m}^{-1} \mathrm{~K}^{-1}\end{array}$ & Sources \\
\hline Anhydrous cement and hydrates & $2 \cdot 8$ & Bouguerra $^{27}$ (on crushed hydrated cement paste) $^{30}$ \\
Water & $0 \cdot 6$ & Farouki $^{30}$ \\
Air & $0 \cdot 025$ & Farouki $^{30}$ \\
\hline
\end{tabular}




$$
\lambda_{l}+\frac{A_{l}}{1-\frac{A_{l}}{3 \lambda_{l}}} \leqslant \lambda^{*} \leqslant \lambda_{n}+\frac{A_{n}}{1-\frac{A_{n}}{3 \lambda_{n}}}
$$

in which $\lambda_{1} \leqslant \lambda_{2} \leqslant \ldots \leqslant \lambda_{n}$ are the thermal conductivities of phases $1,2, \ldots, n$ of the material, respectively

$$
A_{j}=\sum_{i \neq 1 j}^{n} \frac{V_{i}}{\frac{1}{\lambda_{i}-\lambda_{j}}+\frac{1}{3 \lambda_{j}}}
$$

where $\lambda_{i}$ and $V_{i}$ are the thermal conductivity (in $\mathrm{W} \mathrm{m}^{-1}$ $\mathrm{K}^{-1}$ ) and the volume fraction of phase $i$ of the material, respectively.

The results of the simulation, calculated from equations (9) and (10), are presented in Fig. 6. The comparison between simulated and experimental results reveals that

(a) On the one hand, both models give a correct bounding of the linear part of the experimental curve. The Hashin and Shtrickman's model, furthermore, makes it possible to obtain a more precise interval, which confirms that fresh cement paste structure can be considered as isotropic.

(b) On the other, both models do not account for the 'apparent' thermal conductivity peak observed at about $30 \%$ of hydration.

\section{Philip and De Vries' analysis (PDVA)}

As demonstrated by Krischer and Kröll, ${ }^{26}$ the vapour diffusive transport contributes to heat transfer processes within wet porous media through the evaporationcondensation mechanism (water evaporates from the pore hot surfaces, then, migrates by gaseous diffusion process and condenses on the cold surfaces, thus transferring its latent heat vaporisation).

Considering the case of fresh cement paste, it is

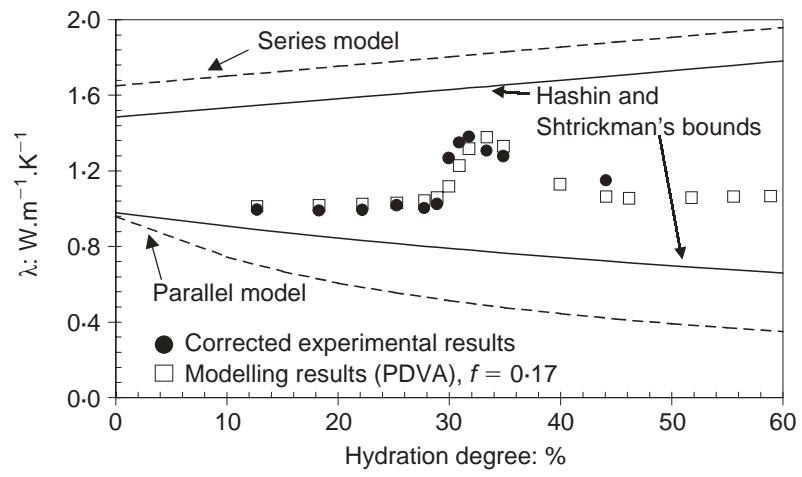

Fig. 6. Determination of the interval to which the measured 'apparent' thermal conductivity (corrected results) belongs, using different multiphase models (series/parallel models and Hashin and Shtrikman's model) and comparison with the "apparent" thermal conductivity computed using PDVA $(f=0 \cdot 17)$ known that the hydration process affects the material microstructure doubly: first, through the creating of internal porosity; and second through the consumption of water by the chemical reactions. The combination of both phenomena leads to some phase changes (liquid water-vapour) and to the creation of interfaces (meniscuses) between liquid and water vapour. The decrease in the internal relative humidity measured during cement paste hydration is the result of the formation of these meniscuses (Fig. 7).

The classical Philip and De Vries' analysis (PDVA) $)^{12-14}$ allows for the consideration of the evaporation-condensation mechanism, which occurs within non-saturated porous media submitted to relatively high temperatures. This analysis has been already applied successfully on hardened civil engineering materials (wood concrete, ${ }^{27}$ autoclaved aerated concrete ${ }^{28}$ for example). Originally, the Philip and De Vries' analysis can only be applied to non-reactive bodies. ${ }^{12}$ In spite of this, we have chosen to use it with a view to examining whether it could give a correct order of magnitude for the experimental results obtained on hardening cement paste.

In the theoretical framework proposed by Philip and De Vries, the heat flow density, $Q$, inside wet porous media is written as

$$
Q=-\lambda_{0} \nabla T+L_{v} J_{v}
$$

in which $\lambda_{0}$ is the 'pure' thermal conductivity (Fourier's law) in $\mathrm{W} \mathrm{m}^{-1} \mathrm{~K}^{-1} ; \nabla T$ is the temperature gradient (in $\mathrm{Km}^{-1}$ ); $L_{v}$ is the water latent heat of vaporisation (in $\mathrm{J}$ $\mathrm{kg}^{-1}$ ); and $J_{v}$ is the mass flow of water vapour (in $\mathrm{kg}$ $\mathrm{s}^{-1} \mathrm{~m}^{-2}$ ). The term $L_{v} J_{v}$ represents the evaporationcondensation effects. The amount of sensible heat transferred is negligible because the vapour density value remains low and the latent heat vaporisation value is high compared to the specific heat of water. The vapour flow density $J_{v}$ can be expressed as

$$
J_{v}=-f D_{v a} \frac{P}{P-P_{v}} \frac{M}{R T} \nabla P_{v}
$$

a specific application of Fick's law, in which $P$ is the total pressure (in $\mathrm{N} \mathrm{m}^{-2}$ ), $P_{v}$ the partial pressure of

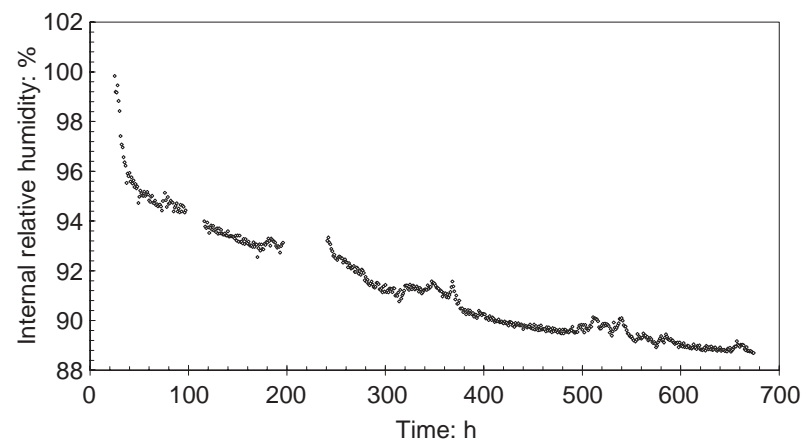

Fig. 7. Evolution of the internal relative humidity of fresh cement paste 
water vapour (in $\mathrm{N} \mathrm{m}^{-2}$ ); $M$ its molar mass (in $\mathrm{kg}$ $\mathrm{mol}^{-1}$ ); $R$ the perfect gas constant (in $\mathrm{J} \mathrm{mol}^{-1} \mathrm{~K}^{-1}$ ); $D_{v a}$ the diffusion coefficient of water vapour in air (in $\mathrm{m}^{2} \mathrm{~s}^{-1}$ ); $T$ the temperature (in $\mathrm{K}$ ) and $f$ a dimensionless factor taking the tortuosity effect of the porous medium into account. Assuming water vapour as a perfect gas and considering a very high moisture content (relative humidity $\varphi \approx 100 \%$ during the first hours of hydration), then

$$
P_{v}=\varphi \cdot P_{v s} \approx P_{v s}
$$

where $P_{v s}$ is the saturation vapour pressure (in $\mathrm{N} \mathrm{m}^{-2}$ ).

Therefore, when neglecting in first approximation the moisture rate gradient, equation (12) becomes

$$
J_{v}=-f D_{v a} \frac{P}{P-P_{v s}} \frac{M}{R T} \frac{d P_{v s}}{d T} \nabla T
$$

When equation (14) is introduced into equation (11), we obtain

$$
Q=-\left[\lambda_{0}+f L_{v} D_{v a} \frac{P}{P-P_{v s}} \frac{M}{R T} \frac{d P_{v s}}{d T}\right] \nabla T=-\lambda^{*} \nabla T
$$

which is the classical form of Fourier's law, if the concept of 'apparent' thermal conductivity $\lambda^{*}$ of the material is assumed.

$$
L_{v} D_{v a} \frac{P}{P-P_{v s}} \frac{M}{R T} \frac{d P_{v s}}{d T}
$$

Dimensions are homogeneous with thermal conductivity ones. This term, which is generally noted $\lambda_{\text {diff }}$, represents the 'apparent' contribution of water vapour diffusion to heat transfer. Its consideration for the calculation of the 'apparent' thermal conductivity of wet porous materials can take different forms. De Vries $^{14}$ advises the use of $\left(\lambda_{\text {diff }}+\lambda_{a}\right)$ for the effective thermal conductivity of the air component, where $\lambda_{a}$ is the normal thermal conductivity of air whereas Bouguerra $^{27}$ and Laurent et al. $^{28}$ use the relationship presented in equation (15) and obtain the following expression for $\lambda^{*}$

$$
\lambda^{*}=\lambda_{0}+f \lambda_{\text {diff }}
$$

The expression of $J_{v}$ proposed by Crausse et al. ${ }^{29}$ is slightly different since the authors explicitly consider the volume content $a$ of the gaseous phase. They obtain the expression of the 'apparent' thermal conductivity $\lambda^{*}$ from

$$
\lambda^{*}=\lambda_{0}+\rho_{l} L_{v} D_{T v}
$$

where

$$
D_{T v}=\beta a D_{v a} \frac{P}{P-P_{v}} \frac{M}{R T} \frac{1}{\rho_{l}}\left[\varphi \frac{d P_{v s}}{d T}+P_{v s}\left(\frac{\partial \varphi}{\partial T}\right)_{\theta}\right]
$$

in which $\beta$ is a dimensionless factor taking the geometrical influence of the porous media on vapour diffusion into account; and $\theta$ is the volume water content of the material. Considering, like previously, a constant relative humidity $\varphi \approx 100 \%$, equation (18) becomes

$$
D_{T v}=\beta a D_{v a} \frac{P}{P-P_{v}} \frac{M}{R T} \frac{1}{\rho_{l}} \frac{d P_{v s}}{d T}
$$

Introducing equation (19) into equation (17), $\lambda^{*}$ becomes

$$
\lambda^{*}=\lambda_{0}+\beta a L_{v} D_{v a} \frac{P}{P-P_{v}} \frac{M}{R T} \frac{d P_{v s}}{d T}
$$

The identification of the different parameters shows that factor $f$, found in equation (16), corresponds to factor $\beta a$ used in equation (20). Considering the high moisture content rate, the only difference between both expressions of $\lambda^{*}$ is the explicit introduction, by Crausse et al., ${ }^{29}$ of the value of volume air content $a$.

Experimental results ${ }^{16,27,28}$ show that $f$ can be considered as a unique function of the material saturation rate $S$. In practice, $f$ is determined by measuring $\lambda^{*}$ at different temperatures and by assuming that, at low temperature (from 0 to $20^{\circ} \mathrm{C}$ ), evaporation-condensation effects can be neglected (then equation (16) gives $\left.\lambda^{*}=\lambda_{0}\right)$. Therefore, factor $f$ can be expressed as

$$
f(S)=\frac{\lambda^{*}(S, T)_{\text {measured }}-\lambda_{0}(S)}{\lambda_{\text {diff }}(T)}
$$

Fitting this to our case, we consider that

(a) The value of $\lambda_{0}$ changes during the hydration process, since, in autogenous conditions, the saturation rate is a direct function of both hydration degree and initial water content of the cement paste. In first approximation, the evolution of $\lambda_{0}$ can be considered linear within the interval constituted by the 'apparent' thermal conductivity measured at $t=1 \mathrm{~h}$ $\left(T=25.65^{\circ} \mathrm{C} ; \alpha=12.74 \%\right)$, denoted $\lambda_{1}^{*}$, and the same parameter measured at $t=73 \mathrm{~h}\left(\mathrm{~T}=21.33^{\circ} \mathrm{C}\right.$; $\alpha=58 \cdot 88 \%$ ), denoted $\lambda_{2}^{*}$. Therefore, $\lambda_{0}$ becomes

$$
\lambda_{0}(\alpha)=\frac{\lambda_{2}^{*}-\lambda_{1}^{*}}{46 \cdot 14} \cdot(\alpha-58 \cdot 88)+\lambda_{2}^{*}(\alpha \text { in } \%)
$$

(b) For a given material, the $\lambda_{\text {diff }}$ value depends on the internal pressure of the gaseous phase, the temperature, and the relative humidity of the material. ${ }^{30}$ At atmospheric pressure and for a relative humidity value close to $100 \%$, the following expression, already used by Krischer and Kröll, ${ }^{26}$ can be applied

$\lambda_{\text {diff }}=0.02213 \times \exp (0 \cdot 054198 . T)\left(T\right.$ in $\left.{ }^{\circ} \mathrm{C}\right)$

where $T$ is the temperature of the cement paste measured by the thermocouples embedded in the material (see Fig. 3).

(c) Our experimental results cannot be used to 
determine factor $f$. However, we know that, at an early age, the saturation rate of cement paste is high. Furthermore, the experiments carried out on hardened wood concrete and autoclaved concrete have shown that, within the range of high saturation rate, the value of $f$ does not exceed $0 \cdot 2$. So, in order to achieve some simulations and compare them with our experimental results, we consider, in first approximation, that $f$ remains constant. Different $f$-values are, then, simulated.

The experimental and simulated results, obtained from equations (22) and (23), are presented in Fig. 6.

It reveals that, for $f=0 \cdot 17$, PDVA gives a good order of magnitude of the experimental results.

However, a small difference between the experimental peak of the 'apparent' thermal conductivity evolution of fresh cement paste and the theoretical peak calculated by mean of PDVA appears.

Different reasons may be put forward to explain this difference. PDVA does not consider reactive and shrinking materials (it is the case of fresh cement paste). In this type of material, complex physicochemical processes take place locally. Two phenomena in competition are in progress: first the hydration reactions, which correspond to a consumption of water; and second, the increasing of temperature, which leads to the evaporation of water in the internal porosity. Therefore, the quantity of water available for evaporation-condensation transfers is continuously modified. At the present time, it is not possible to take this chemical evolution of the material into account through the analysis developed by De Vries and Philip.

Moreover, moisture displacements inside the material have been neglected. These displacements, combined with the temperature gradient induced by the exothermic feature of cement hydration, may affect the 'apparent' thermal properties of the material.

\section{Conclusion}

This paper examined the thermal behaviour of fresh cement paste maintained in autogenous conditions shows a variation in its 'apparent' thermal conductivity at very early ages. From the comparison between the experimental results and the simulations presented in this paper, the following main conclusions can be drawn.

(a) The models simply based on the linear chemical evolution approach (series and parallel model and Hashin and Shtrikman's model) cannot simulate the 'apparent' thermal conductivity peak observed at very early ages of the cement paste.

(b) Considering the existence of evaporation-condensation phenomena due to the structural changes of the material, the Philip and De Vries' analysis ${ }^{12-14}$ has been carried out and has made it possible to achieve a better agreement with the experimental results. However, a limited time lag between modelled and experimental results is observed.

(c) Further experimental work is necessary, especially as regards isothermal conditions, to improve our knowledge of the phenomenon observed and get closer to previous experimental and theoretical studies carried out in isothermal conditions. ${ }^{16}$ For this purpose, a specific device is currently being developed within the laboratory. This device will be used to study smaller fresh cement paste samples under different selected isothermal curing temperatures. From a theoretical point of view, the integration of deformation and chemical reactions into the equation set may be achieved, by considering, for example, the larger framework of the thermodynamics field of nonsaturated reactive porous media. ${ }^{31}$

\section{References}

1. ARnOld P. J. Thermal conductivity of masonry materials. Journal of the Institution of Heating and Ventilating Engineers, 1969, 37, 101-117.

2. Whiting D., Litvin A. and Goodwin S. E. Specific heat of selected concrete. ACI Journal, 1978, 75, 299-305.

3. Morabito P. Measurement of the thermal properties of different concretes. High Temperatures High Pressures, 1989, 21, No. 1, 51-59.

4. XU Y. and Chung D. D. L. Increasing the specific heat of cement paste by admixture surface treatments. Cement and Concrete Research, 1999, 29, No. 7, 1117-1121.

5. XU Y. and Chung D. D. L. Effect of sand addition on the specific heat and thermal conductivity of cement. Cement and Concrete Research, 2000, 30, No. 1, 59-61.

6. Bastian G. and Khelidj A. Propriétés thermophysiques d'un béton fraîchement coulé. Bulletin de Liaison du Laboratoire des Ponts et Chaussées, 1995, 200, 25-35.

7. De Schutter G. and Taerwe L. Specific heat and thermal diffusivity of hardening concrete. Magazine of Concrete Research, 1995, 47, No. 172, 203-208.

8. Gibbon G. J. and Ballim Y. Determination of the thermal conductivity of concrete during the early stages of hydration. Magazine of Concrete Research, 1998, 50, No. 3, 229-235.

9. Copeland L. E., Kantro D. L. and Verbeck G. Chemistry of hydration of cement. Proceedings of the 4th International Symposium on Chemistry of Cement, Washington, DC, 1960, pp. 429-465.

10. Neville, A. Properties of Concrete. Pitman, London, 1975.

11. TaYlor H. F. W. Cement Chemistry. San Diego, Academic Press Limited, 1990.

12. Philip J. R. and De VRies D. A. Moisture movement in porous material under temperature gradients. Transactions of the American Geophysical Union, 1957, 38, 222-232.

13. De VRies D. A. Simultaneous transfer of heat and moisture in porous media. Transactions of the American Geophysical Union, 1958, 39, No. 5, 909-916.

14. De Vries D. A. The theory of heat and moisture transfer in porous media revisited. International Journal of Heat and Mass Transfer, 1987, 30, No. 7, 1343-1350.

15. FLYNN D. R. Response of high performance concrete to fire conditions: Review of thermal property data and measurement techniques. Final report, National Institute of Standards and Technology, GCR 99-767, 1999.

16. Moyne C., Azizi S. and Degiovanni A. Thermal con- 
ductivity of wet porous media: Theoretical analysis and experimental measurements. Proceedings of the 6th International Drying Symposium IDS'88, Versailles, 1988, pp. 85-92.

17. Carslaw H. S. and JAeger J.-C. Conduction of Heat in Solids. Oxford University Press, London, 1959.

18. TAPLIN J. M. A method of following the hydration reaction in Portland cement paste. Australian Journal of Applied Science, 1959, 10, No. 3, 329-345.

19. GEIKER M. Measurements of chemical shrinkage and a systematic evaluation hydration curves by means of the dispersion model. $\mathrm{PhD}$ thesis, Technical University of Denmark, 1983.

20. Kada-Benameur H., Wirquin E. and Duthoit B. Determination of apparent activation energy of concrete by isothermal calorimetry. Cement and Concrete Research, 2000, 30, No. 2, 301-305.

21. Bogue R. H. La Chimie du Ciment Portland. Eyrolles, Paris, 1952.

22. Maltais Y. and Marchand J. Influence of curing temperature on cement hydration and mechanical strength development of fly ash mortars. Cement and Concrete Research, 1997, 27, No. 7, 1009-1020.

23. Salmon-Gandonniere A. DEA Dissertation, IUT de SaintNazaire, France, 1998.

24. DemirboĞA R. Influence of mineral admixtures on thermal conductivity and compressive strength of mortar. Energy and Buildings, 2003, 35, No. 2, 189-192.
25. Le Chatelier H. Sur les changements de volume qui accompagnent le durcissement des ciments. Bulletin de la Société d'Encouragement pour l'Industrie Nationale, 1900, 5, 54-57.

26. Krischer O. and KröLl K. Technique du Séchage. Trad. CETIAT, Orsay, 1963.

27. Bouguerra A. Contribution à l'étude d'un procédé de valorisation de déchets argileux: comportement hygrothermique des matériaux élaborés. PhD thesis, INSA de Lyon, France, 1997.

28. Laurent J.-P. and Guerre-Chaley C. Influence de la teneur en eau et de la température sur la conductivité thermique $\mathrm{du}$ béton cellulaire autoclavé. Materials and Structure, 1995, 28, 464-472.

29. Crausse P., Laurent J.-P. and Perrin B. Porous materials hysteretic moisture characteristics : influence on water content distributions in buildings walls. Comparison of two simulation models. Revue Générale de Thermique, 1996, 35, 95-106.

30. FARouki O. T. Thermal Properties of Soils. Trans Tech Publication, Clausthal-Zellerfeld, 1986.

31. Coussy O. Mechanics of Porous Continua. Wiley, Chichester, 1995. 